\title{
Diabetic Foot Disease-Incidence and Risk Factors: A Clinical Study
}

\author{
${ }^{1}$ Rakesh Sharma, ${ }^{2}$ Rajesh Kapila, ${ }^{3}$ Ashwani K Sharma, ${ }^{4}$ Jagsir Mann
}

\section{ABSTRACT}

Diabetic foot disease is one of the most common, yet dreaded long-term complication of diabetes mellitus, especially in developing countries. It is the single-most common cause of nontraumatic lower limb amputations. Various studies worldwide have shown an incidence of diabetic foot to be 15 to $25 \%$. Elderly males who are smokers and have habit of alcohol intake and have long duration of type 2 diabetes are at major risk for this problem. The other significant risk factors are: Poor glycemic control, neuropathy, angiopathy, nephropathy, and retinopathy. Management of diabetic foot disease involves a multidisciplinary approach. The present study was conducted with the aim to know about the prevalence of the incidence of diabetic foot disease in diabetic patients and to enumerate the different risk factors associated with it for the occurrence of diabetic foot disease in such patients at the time of presentation.

Over a period of 1 year, a prospective study involving 1,016 diabetic patients as per World Health Organization (WHO) criteria were screened for diabetic foot disease. All cases were graded as per University of Texas classification. Incidence of diabetic foot disease was calculated and the risk factors were identified through proper history taking, clinical evaluation, and specialized tests as and when required.

Some of the common risk factors identified in our study were: Elderly males from poor families having long-term type 2 diabetes and who were smokers and alcoholics. Many of these patients had other systemic complications of diabetes in the form of neuropathy, retinopathy, angiopathy, and nephropathy as well. A very important, yet easily modifiable risk factor was poor glycemic control. Our conclusion from the study is being that the diabetic foot disease is much common than anticipated in diabetes mellitus patients; it is on the rise and the resultant morbidity is very crippling to the affected individuals. Therefore it is very important to identify the risk factors and educate patients about them, especially the modifiable risk factors, so that its incidence and the morbidity can be brought down significantly.

Keywords: Angiopathy, Diabetes, Diabetic foot disease, Neuropathy.

How to cite this article: Sharma R, Kapila R, Sharma AK, Mann J. Diabetic Foot Disease_-Incidence and Risk Factors: A Clinical Study. J Foot Ankle Surg (Asia-Pacific) 2016;3(1):41-46.

\footnotetext{
${ }^{1-3}$ Associate Professor, ${ }^{4}$ Junior Resident

1,2,4 Department of Orthopaedics, Government Medical College Amritsar, Punjab, India

${ }^{3}$ Department of Medicine, Government Medical College Amritsar, Punjab, India
}

Corresponding Author: Rakesh Sharma, Associate Professor, Department of Orthopaedics, Government Medical College, Amritsar, Punjab, India, Phone: +919888182446 e-mail: drrksharma50@yahoo.com

\section{Source of support: Nil}

Conflict of interest: None

\section{INTRODUCTION}

Diabetes mellitus is assuming pandemic proportions worldwide and so are its associated long-term complications. In addition to the delayed complications like nephropathy, retinopathy, neuropathy, etc., diabetic foot disease is one of the most common and dreaded complication of diabetes mellitus, especially in developing countries. According to the World Health Organization (WHO) and International Working Group on the Diabetic Foot, diabetic foot is defined as the foot of diabetic patients with ulceration, infection, and/or destruction of the deep tissues, associated with neurological abnormalities and various degrees of peripheral vascular disease in the lower limb.

Diabetic foot incidence in diabetic persons increased from $0.7 \%$ in 1980 to $2.7 \%$ in $1999 .{ }^{1}$ Diabetic foot is a leading cause of hospital admission among people with diabetes mellitus. It is assessed that during their life time $15 \%$ of diabetic people develop foot ulcers at the most prone site of big toe and a good number of them (14-24\%) land into amputation. ${ }^{2}$ Diabetic foot is the single-most common cause of nontraumatic lower limb amputation, accounting for almost 40 to $60 \%$ of nontraumatic amputations. ${ }^{3}$

Various risk factors associated with increased chances of developing diabetic foot disease are:

- Sex (more common in males)

- Older age

- Duration of diabetes for more than 10 years

- Structural foot deformities

- History of previous ulcer

- Associated systemic disorders, such as:

- Peripheral neuropathy

- Peripheral vascular disease

- Nephropathy/retinopathy

- Poor glycemic control

- Poor socioeconomic background/smoking.

Neuropathy appears to be the single-most important factor not only in developing diabetic foot but also in delaying the healing process. Patients having sensory loss appear to have seven times increased risk of developing foot ulcer. Origin of neuropathy remains unclear. ${ }^{4}$ It may be due to insufficiency of intrinsic blood supply to 
peripheral nerves, may be autoimmune ${ }^{5}$ or microvascular ischemia caused by the accumulates of advanced glycosylated endproducts. ${ }^{6}$

Peripheral vascular disease is another important risk factor and is mainly due to widespread and often multisegmental atherosclerosis of large vessels of the leg. It is often bilateral and distal involving tibial and peroneal vessels below knee due to unknown reason. ${ }^{7}$

Though there are three main classification systems for diabetic foot, University of Texas Wound Classification ${ }^{8}$ system is the most common and has been used in our study too.

Management of diabetic foot disease involves a multidisciplinary team approach involving orthopedic surgeon, diabetologist, vascular surgeon, general surgeon, pathologist, psychiatrist, occupational, and physical therapist and their approach itself can reduce the incidence of amputation by up to $85 \% .{ }^{9}$

The main aim of the present study was to determine the incidence of diabetic foot disease among the diabetic patients, to find out the associated risk factors in its development, and to study the pattern of various grades of diabetic foot at the time of presentation.

\section{MATERIALS AND METHODS}

This is a prospective study conducted at a tertiary care centre during a period of 1 year between 2011 and 2012. All 1,016 diabetic patients (WHO criteria) were included in the study after taking consent and incidence of diabetic foot was calculated as per formula.

Incidence $=\frac{\begin{array}{c}\text { Number of new cases of specific disease } \\ \text { during the given period of time }\end{array}}{\text { Population at risk during that period }} \times 1000$

All cases of diabetic foot were graded as per University of Texas Wound Classification (Table 1). ${ }^{8}$

Once the patient was selected for study, he/she was assessed in relation to age, sex, socioeconomic status, duration and type of diabetes, history of smoking, family history of diabetic mellitus, earlier foot ulcers, and the treatment taken.

Clinical evaluation of the patient was done by general physical examination. Neurological assessment was performed, using the Semmes-Weinstein 5.07 monofilament for touch, vibration sense by tuning fork, and the motor reflexes using rubber hammer. Vascular examination was done to show the presence/absence of peripheral pulses and ophthalmological examination was done to rule out retinopathy. Assessment of glycemic control was done by measuring mean $\mathrm{HbA1c}$, fasting, and mean random blood glucose. Fasting plasma glucose up to $120 \mathrm{mg} / \mathrm{dL}$ was taken as good, between 120 and $150 \mathrm{mg} / \mathrm{dL}$
Table 1: University of Texas Wound Classification for diabetic foot ulcers

Grade 0: Pre- or postulcerative lesion completely epithelialized Stage A Without infection or ischemia

Stage B With infection

Stage C With ischemia

Stage D With infection and ischemia

Grade 1: Superficial wound not involving tendon, capsule, or bone

$\begin{array}{ll}\text { Stage A } & \text { Without infection or ischemia } \\ \text { Stage B } & \text { With infection } \\ \text { Stage C } & \text { With ischemia } \\ \text { Stage D } & \text { With infection and ischemia }\end{array}$

Grade 2: Wound penetrating to tendon or capsule

Stage A Without infection or ischemia

Stage B With infection

Stage C With ischemia

Stage D With infection and ischemia

Grade 3: Wound penetrating to bone or joint

Stage A Without infection or ischemia

Stage B With infection

Stage C With ischemia

Stage D With infection and ischemia

as fair, and above $150 \mathrm{mg} / \mathrm{dL}$ as poor. Specialized investigations, such as Color Doppler, were done if it was presumed to be of importance to quantitatively assess the blood flow or to spot out the occluded area.

\section{OBSERVATIONS}

Following the observations, various risk factors for the development of diabetic foot ulcers were made among all the surveyed $(1,016)$ diabetic patients (Table 2). Different grades of the diabetic foot ulcers were observed as per the classification used in this study (Table 3 and Figs 1A to D).

Interesting facts were revealed when we compared alcohol drinkers $v s$ nondrinkers. Of the 613 nondrinkers only $80(13.05 \%)$ had diabetic foot disease and the number increased significantly in drinkers, where of the 403 such patients, 113 (28.04\%) had diabetic foot disease.

We inferred from the observations that risk factors, such as male gender, longer duration of disease, type-2 diabetes, smoking, alcohol intake, poor glycemic control, neuropathy, nephropathy, retinopathy, peripheral vascular disease, and treatment protocol with Insulin, seem to be statistically highly significant in the development of diabetic foot disease. The most important, yet modifiable risk factor being the poor glycemic control. Smoking and alcohol intake are other modifiable risk factors. Among the treatment options, Insulin was found to be highly significant in the development of foot ulcers as compared to the oral hypoglycemic agents. These observations can 


\begin{tabular}{|c|c|c|c|c|}
\hline & \multirow[b]{2}{*}{ Parameter/Risk factor } & \multicolumn{2}{|c|}{ Patient screened: 1,016 } & \multirow[b]{2}{*}{$p$-value } \\
\hline & & DFU cases & Non-DFU cases & \\
\hline 1 & Incidence & $193(18.99 \%)$ & 823 & \\
\hline 2 & Mean age (years) & $59.09 \pm 10.30$ & $55.41 \pm 20.93$ & 0.018 \\
\hline \multirow[t]{3}{*}{3} & Sex: & & & \\
\hline & Male & 139 & 473 & $<0.001$ \\
\hline & Female & 54 & 350 & \\
\hline 4 & Mean duration of diabetic mellitus in years & 13.36 & 10.97 & $<0.001$ \\
\hline \multirow[t]{3}{*}{5} & Fasting blood sugar: & & & \\
\hline & $121-150 \mathrm{mg} \%$ & 10 & 233 & $<0.001$ \\
\hline & $>150 \mathrm{mg} \%$ & 183 & 590 & \\
\hline 6 & Mean random blood sugar & 297.22 & 237.29 & $<0.001$ \\
\hline \multirow[t]{3}{*}{7} & Peripheral neuropathy & & & \\
\hline & Not present & 8 & 334 & $<0.001$ \\
\hline & Present & 185 & 489 & \\
\hline \multirow[t]{3}{*}{8} & Peripheral vascular disease & & & \\
\hline & Nonpalpable peripheral pulse & 159 & 794 & $<0.001$ \\
\hline & Palpable & 34 & 29 & \\
\hline \multirow[t]{3}{*}{9} & Nephropathy & & & \\
\hline & Present & 136 & 703 & $<0.001$ \\
\hline & Not present & 57 & 120 & \\
\hline \multirow[t]{3}{*}{10} & Retinopathy & & & \\
\hline & Present & 146 & 468 & $<0.001$ \\
\hline & Not present & 47 & 355 & \\
\hline \multirow[t]{3}{*}{11} & Any h/o previous ulcer & & & \\
\hline & Present & 120 & 117 & $<0.001$ \\
\hline & Not present & 73 & 706 & \\
\hline \multirow[t]{3}{*}{12} & Smoking & & & \\
\hline & Present & 107 & 177 & $<0.001$ \\
\hline & Not present & 86 & 646 & \\
\hline \multirow[t]{4}{*}{13} & Socioeconomic status & & & \\
\hline & Upper class & 0 & 1 & $<0.027$ \\
\hline & Middle class & 93 & 482 & \\
\hline & Lower class & 100 & 340 & \\
\hline \multirow[t]{4}{*}{14} & Diabetic treatment undertaken & & & \\
\hline & No drug & 36 & 71 & $<0.001$ \\
\hline & Insulin & 75 & 273 & \\
\hline & Oral hypoglycemic & 82 & 479 & \\
\hline \multirow[t]{3}{*}{15} & Type of diabetes & & & \\
\hline & Type 1 & 8 & 14 & $<0.036$ \\
\hline & Type 2 & 185 & 809 & \\
\hline \multirow[t]{3}{*}{16} & Previous foot deformity & & & \\
\hline & Present & 149 & 240 & $<0.001$ \\
\hline & Absent & 44 & 583 & \\
\hline
\end{tabular}

Table 3: Different grades of diabetic foot ulcers as per University of Texas classification

\begin{tabular}{lll}
\hline Grade & No. of cases & Percentage \\
\hline 0 & $41(\mathrm{~A}-12, \mathrm{~B}-14, \mathrm{C}-2, \mathrm{D}-13)$ & 21.24 \\
1 & $50(\mathrm{~A}-7, \mathrm{~B}-29, \mathrm{C}-8, \mathrm{D}-6)$ & 25.90 \\
2 & $45(\mathrm{~A}-5, \mathrm{~B}-19, \mathrm{C}-5, \mathrm{D}-16)$ & 23.32 \\
3 & $57(\mathrm{~A}-13, \mathrm{~B}-13, \mathrm{C}-15, \mathrm{D}-16)$ & 29.54 \\
\hline
\end{tabular}

help us to educate the diabetic people to control and minimize the modifiable risk factors so as to reduce the risk of diabetic foot disease and the resultant morbidity.

\section{DISCUSSION}

Diabetic foot disease is one of the most feared complications of diabetes mellitus. Ultimately, as an end point, it can lead to complete loss of vascularity and dead and necrotic tissues and thus amputation, which is always a traumatic experience and associated with significant morbidity and mortality, along with immense social, psychological, and financial consequences. So herein has the importance of identifying risk factors in the development of diabetic foot so that these amputations can be minimized. 

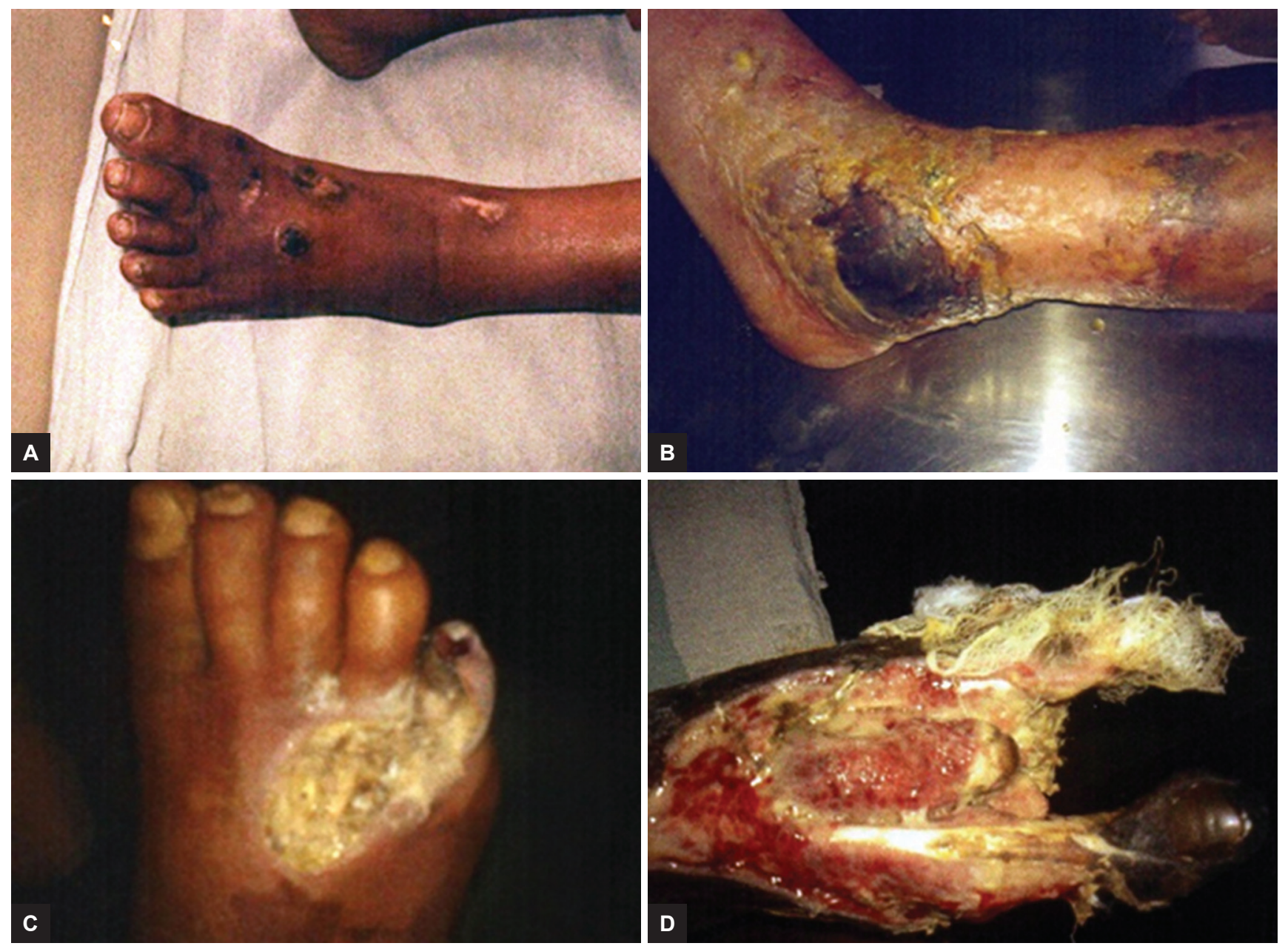

Figs 1A to D: Different grades of diabetic foot ulcers: (A) Grade 0, stage B: Commonest presentation among grade 0 ( $7.25 \%$ of total DFUs); (B) grade 1, stage B: Commonest presentation among grade 1, (15.03\% of DFUs); (C) grade 2, stage B: Commonest grade 2 presentation ( $9.84 \%$ of DFUs); and (D) grade 3, stage D: Commonest grade 3 presentation ( $8.29 \%$ of DFUs)

The incidence of diabetic foot in our study is $19 \%$, which is comparable to other literatures which show an incidence of 15 to $25 \%$, especially in a prospective study of 248 patients from three large diabetic foot centres. ${ }^{10}$

As per the classification system, the maximum incidence of diabetic foot was grade $3(30.05 \%)$ and as per substaging was stage B $(38.86 \%)$, i.e., infection but no loss of blood supply. In a study of 193 diabetic foot patients, $46.91 \%$ patients were stage A, while $29.29 \%$ belonged to stage B of grade $3 .{ }^{11}$ Probably, a large number of patients in our study were grade 3, stage B due to illiteracy, walking bare foot, religious and economic compulsion, self-treatment, and reporting late to tertiary care centre.

The mean age of diabetic foot in our study was $55.09 \pm 10.30$ years, which correlates with a study that found mean age to be $57.04 \pm 11.63$ years. ${ }^{12}$ Males were much more commonly involved (78.64\%), which have been clearly shown in various studies in the literature as well. ${ }^{11,13,14}$ In Indian conditions, males being mostly the primary earners in families, their outdoor activity is higher compared to that of females, and added to that the condition of decreased sensation due to neuropathy, they have a higher tendency to be more prone to injury, therefore making them more susceptible to diabetic foot disease.

In this study of diabetic foot patients, $61.81 \%$ were from poor strata and low-income group, which is also found to be a well-known risk factor in some other studies as well. ${ }^{1,15}$ Smoking was another important risk factor $(44.56 \%)$ in our study which correlates well with a study showing $41.4 \%{ }^{16}$ Most of the patients in our study were type 2 diabetes mellitus as shown by various studies. ${ }^{11,12,14,17}$

Mean duration of disease in our study was $13.36 \pm 6.93$ years, which correlates closely with a study showing mean duration of $14.2 \pm 7.4$ years. ${ }^{18}$ Thus, as the duration of disease increases, the chances of developing diabetic foot disease also increase. Poor diabetic control is a highly significant and modifiable risk factor in our study that has been authenticated in various other studies as well. ${ }^{19,20}$ Poor glycemic control lead to glycosylated immune proteins which leave patients more prone to infection. ${ }^{21}$ Thus glycemic control is the most effective therapy for reducing incidence of diabetic foot disease. Peripheral 
neuropathy was seen in $95.85 \%$ of diabetic foot patients in our study, which was seen in many other studies in literature as well. ${ }^{14,22-27}$ Autonomic neuropathy results in the loss of sweating and as such the dryness of the skin can lead to the formation of cracks in the skin and tissues. This coupled with motor neuropathy led to atrophic changes in foot musculature, leading to foot deformity and areas of increased plantar foot pressure. Decreased sense of touch makes an individual unaware of minor traumas which can lead to ulceration. ${ }^{28}$

In our study, $17.62 \%$ patients had signs of peripheral vascular disease, which is much higher than another Indian study showing $13 \%$ of such cases. ${ }^{14}$ Peripheral vascular disease is probably less in Indian studies, probably due to shorter duration of diabetes, less number of smokers, and ethnicity-related reasons than in developed countries $(36.42 \%) .^{12}$

Nephropathy was seen in $29.55 \%$ of cases as seen in various studies. ${ }^{1,26,29,30}$ Similarly, retinopathy was present in $75.65 \%$ cases as seen in another study. ${ }^{16}$ It was unclear whether the renal and ocular conditions were simply associations or risk factors. Presence of having ulcers previously (37.82\%) and foot deformity (77.20\%) were found to be strong risk factors in our study as seen in most of the studies. ${ }^{1,28-34}$ Foot deformity leads to formation of abnormal pressure point, mostly at 1st or 5 th metatarsal head leading to skin breakdown and ulceration. If we correlate the diabetic foot disease to the treatment history for the diabetes, the dreaded problem of diabetic foot was highest in patients who have not had any treatment (33.64\%), followed by insulin users $(21.99 \%)$, and then followed by oral hypoglycemic agents (14.43\%). Surprisingly, another study has shown insulin to be a known risk factor for diabetic foot disease. ${ }^{33}$ Perhaps untreated patients were left out in this study.

\section{CONCLUSION}

From the present study we conclude that diabetic foot is common, yet potentially disastrous complication of diabetes mellitus if not managed effectively. Diabetic foot disease is more common in patients with longstanding diabetes, retinopathy, nephropathy, low socioeconomic status, smokers, and untreated diabetic patients. Chances of getting diabetic foot increase many folds if the patients develop neuropathy, PVD, poor glycemic control, and previous history of ulcers. Management of diabetic foot, therefore, is a multidisciplinary approach that requires not only medical and surgical management but also patient's education at all levels. The only way going forward for minimizing the morbid condition of diabetic foot disease is to educate the patients regarding its modifiable risk factors and the effective prevention so as to reduce the chances of development of primary ulcers.

\section{REFERENCES}

1. Boulton AJM, Armstrong DG. The diabetic foot. In: Clinical diabetes. Elsevier Inc. Chapter 14, 1st ed. 2006. p. 179-195.

2. Power CA. Diabetes mellitus. In: Harrison's Principals of Internal Medicine, McGraw Hill. Chapter 338. 2007. Vol. 1. p. 2275-2302.

3. Pelquist J, Agarth CD. The association between clinical risk factor and outcome of diabetic foot ulcer. Diabetic Res Clin Pract 1992 Oct;18(1):43-53.

4. Thomas PK. Classification, differential diagnosis and staging of diabetic peripheral neuropathy. Diabetes 1997 Sep;46 (Suppl 2):S54-S57.

5. Marvin E. Levin. Foot Lesions in Patients with Diabetes Mellitus. Endocrinology Clinics of North America 1996;25(2): 447-462.

6. Logerf FW, Gary W. Gibbons. Vascular Diseases of the lower extremity in Diabetes Mellitus. Endocrinology Clinics of North America 1996; 25(2):439-445.

7. Edmonds ME, Roberts VC, Watkin PJ. Blood flow in diabetic neuropathic foot. Diabetologica 1982 Jan;22(1):9-15.

8. Armstrong DG, Lavery LA, Harkless LB. Who is at risk for diabetic foot ulceration? Clin Podiatr Med Surg 1998 Jan;15(1): 11-19.

9. Tiivistelmä KHS. Diabetes related foot problems. Duodecim 2009;125(17):1907-1909.

10. Pham H, Armstrong DG, Harvey C, Harkless LB, Giurini JM, Veves A. Screening techniques to identify people at high risk for diabetic foot ulceration: A prospective multicentre trial. Diabetes Care 2000 May;23(5):606-611.

11. Oyibo SO, Jude EB, Tarawneh I, Nguyen HC, Harkless LB, Boulton AJ. A comparison of two diabetic foot ulcer classification systems: the Wagner and the University of Texas wound classification systems. Diabetes Care 2001 Jan;24(1): 84-88.

12. Bansal E, Garg A, Bhatia S, Attri AK, Chander J. Spectrum of microbial flora in diabetic foot ulcers. Ind J Pathol Microbiol 2008 Apr-Jun;51(2):204-208.

13. Viswanathan V, Madhavan S, Rajasekar S, Chamukuttan S, Ambady R. Urban-rural difference in the prevalence of foot complications in south-Indian diabetic patients. Diabetes Care 2006 Mar;29(3):701-703.

14. Morbach S, Lutale JK, Viswanathan V, Möllenberg J, Ochs HR, Rajashekar S, Ramachandran A, Abbas ZG. Regional difference in risk factors and clinical presentation of diabetic foot lesions. Diabet Med 2004 Jan;21(1):91-95.

15. Khanolkar MP, Bain SC, Stephens JW. The diabetic foot. QJM 2008 Sep;101(9):685-695.

16. Parisi MC,Zantut-Wittmann DE,Pavin EJ,MachadoH,Nery M, Jeffcoate WJ. Comparison of three systems of classification in predicting the outcome of diabetic foot ulcers in a Brazilian population. Eur J Endocrinol 2008 Oct;159(4): 417-422.

17. Rooh-Ul-Muqim, Ahmed M, Griffin S. Evaluation and management of diabetic foot according to Wagner's classification. A study of 100 cases. J Ayub Med Coll Abbottabad 2003 JulSep;15(3):39-42.

18. Booya F, Bandarian F, Larijani B, Pajouhi M, Nooraei M, Lotfi J. Potential risk factors for diabetic neuropathy: a case control study. BMC Neurol 2005 Dec 10;5:24.

19. Veves A, Giurini JM, Logerfo FW . The Diabetic Foot ( second edition) Humana Press, Totowa, New Jersey, 2006. p 978-1007. 
20. Lin SD, Lin CJ, Wang AH, Zhao S, Yan L, Wang PH, Du YM, Wang ZJ, Xiao ZH, Ma XY, et al. A multicentre survey on the diabetic foot and its neuropathy in China. Zonghua Yi Xue Za Zhi 2007 May 15;87(18):1241-1244.

21. Gupta SK, Panda S, Singh SK. The etiopathogenesis of the diabetic foot: an unrelenting epidemic. Int J Low Extrem Wounds 2010 Sep;9(3):127-131.

22. Kastenbauer T, Sauseng S, Brath H, Abrahamian H, Irsigler K. The value of the Rydel-Seiffer tuning fork as a predictor of diabetic polyneuropathy compared with a neurothesiometer. Diabet Med 2004 Jun;21(6):563-567.

23. King H, Aubert RE, Herman WH. Global burden of diabetes 1995-2025; prevalence, numerical estimates and projections. Diabetes Care 1998 Sep;21(9):1414-1431.

24. Reiber GE, Vileikyte L, Boyko EJ, del Aguila M, Smith DG, Lavery LA, Boulton AJ. Causal pathways for incident lower extremity ulcers in patients with diabetes from two settings. Diabetes Care 1999 Jan;22(1):157-162.

25. Young MJ, Breddy JL, Veves A, Boulton AJ. The prediction of diabetic neuropathic foot ulceration using vibration perception thresholds: a prospective study. Diabetes Care 1994 Jun;17(6):557-560.

26. Park SA, Ko SH, Lee SH, Cho JH, Moon SD, Jang SA, Son HS, Song KH, Cha BY, Son HY, et al. Incidence of diabetic foot and associated risk factors in type 2 diabetic patients: a five year observational study. Korean Diabetes J 2009 Aug;33(4):315-323.
27. Benotmane A, Mohammedi F, Ayad F, Kadi K, Azzouz A. Diabetic foot lesions: etiologic and prognostic factors. Diabetes Metab 2000 Apr;26(2):113-117.

28. Clemens MW, Attinger CE. Biological basis of diabetic foot. Wound Surg Technol Int 2008;17:89-95.

29. Abbott CA, Carrington AL, Ashe H, Bath S, Every LC, Griffiths J, Hann AW, Hussein A, Jackson N, Johnson KE, et al. The North-West Diabetes foot care study: Incidence of and risk factors for, new diabetic foot ulceration in a community based patient cohort. Diabetic Med 2002 May;19(5):377-384.

30. Peters EJ, Lavery LA. Effectiveness of the diabetic foot risk classification system of the international working group on the diabetic foot. Diabetes Care 2001 Aug;24(8): 1442-1447.

31. Parkins BA, Olaleye D, Zinman B, Bril V. Simple screening tests for peripheral neuropathy in the diabetes clinic. Diabetes Care 2001 Feb;24(2):250-256.

32. Singh N, Armstrong DG, Lipsky BA. Preventing foot ulcers in patients with diabetes. JAMA 2005 Jan 12;293(2):217-228.

33. Boyko EJ, Ahroni JH, Stensel V, Forsberg RC, Davignon DR, Smith DG. A prospective study of risk factors for diabetic foot ulcer: The Seattle Diabetic Foot Study. Diabetes Care 1999 Jul;22(7):1036-1042.

34. Jeffcoate WJ, van Houtum WH. Amputation as a marker of the quality of foot care in diabetes. Diabetologia 2004 Dec;47(12):2051-2058. 